\title{
Surface Phenomena of Deuterized Ethanol Exposed Zircaloy-4 Surfaces
}

\author{
Juyun Park, Se-Won Jung, Mi-Sun Chun, and Yong-Cheol Kang-

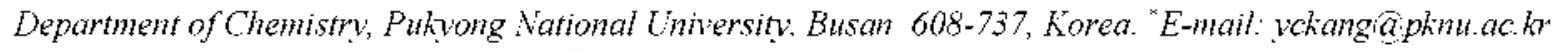 \\ Received April 18, 2009, Accepted Hav t, 2009
}

\begin{abstract}
We report the results of the surface chemistry of deuterized ethanol exposed Zircaloy-4 (Zry-4) surfaces with various amount of $\mathrm{C}_{2} \mathrm{D}_{5} \mathrm{OD}$ exposures at $190 \mathrm{~K}$. This system was examined with Auger electron spectroscopy (AES) and temperature progranmed desorption (TPD) techniques. In TPD study, $\mathrm{D}_{2}$ was evolved at two different desorption temperature regions acconpany ing with broad desorption background. The lower temperature feature at around 520 $\mathrm{K}$ showed first-order desorption kinetics. The high temperature desorption peak at around $650 \mathrm{~K}$ shifted to lower desorption temperature as the exposure of $\mathrm{C}_{2} \mathrm{D}_{5} \mathrm{OD}$ increased. The $\mathrm{Zr}(\mathrm{MNV})$ Auger peak shifted about $2.5 \mathrm{eV}$ from $147 \mathrm{eV}$ to lower electron energy followed by $300 \mathrm{~L}$ of $\mathrm{C}_{2} \mathrm{D}_{5} \mathrm{OD}$ dosing. This implies metallic zirconiun was oxidized by deuterized ethanol adsorption. After stepwise annealing of the oxidized $\mathrm{Zry}-4$ sample up to $843 \mathrm{~K}$, the shifted $\mathrm{Zr}(\mathrm{MNV})$ peak was gradually shifted back to metallic zirconium peak position. After the sample was heated to $843 \mathrm{~K}$, the oxygen content near the $\mathrm{Zry}-4$ surface was recovered to clean surface level. The concentration of carbon, however, was not recovered by annealing the sample.
\end{abstract}

Key Words: Auger electron spectroscopy, Zircaloy-4, Ethanol. Temperature programmed desorption

\section{Introduction}

Due to the low thermal neutron capture cross-section. good corrosion resistance, and adequate mechanical properties. Zircaloy-4 (Zry-4) is often chosen as cladding tube materials in nuclear industry. ${ }^{1,2} \mathrm{Zry}-4$ contains $1.4 \mathrm{wt} \% \mathrm{Sn} .0 .23 \mathrm{wt} \%$ $\mathrm{Fe}, 0.1 \mathrm{wt} \% \mathrm{Cr}$, and $\mathrm{Z}_{\mathrm{r}}$ as the balance component. $\mathrm{Z}_{\mathrm{ry}}+\mathrm{t}$ has been of great concern and investigated with a variety of surfaces in many fields. The corrosion, ${ }^{3 \cdot 9}$ oxidation. ${ }^{10.17}$ and hydrogen absorption kinetics ${ }^{18-23}$ of $\mathrm{Zry}-4$ and its nuclear application have been reported in literatures. Zry-4 oxidation by water $\left(\mathrm{H}_{2} \mathrm{O}\right)$ and steam has been reported in many studies. ${ }^{-4-32}$ Ramsier's group reported that heating $\mathrm{H}_{2} \mathrm{O} / \mathrm{Zry}-4$ surface resulted in molecular desorption of water at both low and high temperatures. Also they investigated that the behavior of water with sulfur dioxide pre-exposed $Z_{r y}-4$ surface.$^{27}$ They studied that adsorption of $\mathrm{SO}_{2}$ caused shift of the $\mathrm{Zr}(\mathrm{MNN})$ Auger electron feature by $3.0 \mathrm{eV}$, while subsequent water adsorption attenuated the sulfur Auger signal and resulted in the development of a zirconium oxide. The effects of adsorbates on the oxidation of $\mathrm{Zry}_{\mathrm{y}}+$ in air and steam were studied by the measurement of the weight gain of specimens. ${ }^{28}$

Reaction of alcohols on transition metal surfaces are of great interest. Ethanol has been receiving considerable attention recently because of its high potential for producing molecular hydrogen to power fuel cells. ${ }^{33-36}$ Ethanol is atractive due to its renewable nature since it can be produced in high yield by fermentation of crops. Because ethanol can be easily transported on board hydrogen generation by reforming is an attractive solution to feed fuel cells. Despite a few papers have studied about interaction of $C_{2} D_{5} O D$ on zirconium, the surface chemistry of ethanol dosed on $\mathrm{Zny}-4$ surface is not well known yet. We report here the results of the thermal effect on the surface chemistry of $\mathrm{C}_{2} \mathrm{D}_{5} \mathrm{OD}$ dosed $\mathrm{Zry}-4$ surface using TPD and AES techniques.

\section{Experimental Section}

The $\mathrm{Zry}-4$ sample used in this study has a thickness of 1.70 $\mathrm{nm}$ and surface area of $9.35 \mathrm{~mm} \times 9.55 \mathrm{~mm}$ in a rectangular shape. It was prepared through many steps of polishing with different meshes of abrasive papers and mechanical polisher (Bueller. gamna alumina. 0.05 micron) for the final step of surface polishing. Then the polished $\mathrm{Zry}-4$ was rinsed with acetone in ultrasonic cleaner for ten minutes. After the sample was rinsed with acetone and then the surface was blown with dry nitrogen gas. The prepared $\mathrm{Zry}-4$ sample was mounted on the custom designed sample holder by spot welding on $\mathrm{Ta}$ wires. The type-K thermocouple was spot welded on the side of the $\mathrm{Zry}-4$ for monitoring temperature. Before the experiment was performing. the sample was cleaned by many cycles of $\operatorname{Ar}^{-}$(99.999\% purity, Aldrich) sputtering followed by annealing to $843 \mathrm{~K}$. During the $\mathrm{Ar}^{+}$sputtering process (IES 5. Omicron). the pressure of $\mathrm{Ar}^{+}$was kept at $1.5 \times 10^{-5}$ Torr for 1 hour in order to make $20 \mu \mathrm{A}$ of a target current. And the Ar fluence was $5.1 \times$ $10^{23} \mathrm{Ar}^{+} / \mathrm{cm}^{2}$ per sputtering cycle. Cleanliness of the sample was confirmed by AES.

For TPD experiments. the sample was facing to the quadrupole mass spectrometer (QMS: Dycor Dymaxion. AMETEK) and the sample temperature was increased at a rate of $1 \mathrm{~K} / \mathrm{s}$ by resistive heating using a feedback $\mathrm{PD}$ controller. The temperature of the sample was monitored by type-K thermocouple spot welded on the side of $\mathrm{Zry}-4$ sample. The sample was cooled down by liquid nitrogen. When the tenperature of the sample reached about $190 \mathrm{~K} . \mathrm{Zry}-4$ was exposed to the gas phase $\mathrm{C}_{2} \mathrm{D}_{5} \mathrm{OD}$ with various exposures. In order to identify the hydrogen produced from the ethanol not from the residual hydrogen the analysis chamber. high purity deuterized ethanol was introduced. The $\mathrm{C}_{5} \mathrm{D} ; \mathrm{OD}(99.5 \%$, atom $\%$ ) was purified through several times of freeze-pump-thaw (FPT) methods before introducing it into UHV chamber. The purity of $\mathrm{C}_{2} \mathrm{D}_{5} \mathrm{OD}$ after several cycles of FPT was checked by QMS. After the sample 
was cooled down to $190 \mathrm{~K} . \mathrm{C} \div \mathrm{D} \leqslant \mathrm{OD}$ was backfilled into the main analysis chamber through a precision leak valve kept the pressure at $1.0 \times 10^{-6}$ Torr during gas dosing and the exposure time was measured until the pressure reached to $5.0 \times 10^{.9}$ Torr. then the sample was linearly heated up to $8+3 \mathrm{~K}$. The possible desorption species from the deuterized ethanol adsorbed $\mathrm{Zry}-4$ surfaces. such as $\mathrm{H}_{2} . \mathrm{HD}, \mathrm{D}_{2}, \mathrm{H}_{2} \mathrm{O}, \mathrm{D}_{2} \mathrm{O} . \mathrm{CO}$. and $\mathrm{CD}_{3} \mathrm{O}$ were monitored applying multiple ion monitoring (MIM) mode in QMS.

The base pressure of UHV analysis chamber was kept at low $10^{-115}$ Torr range. The details of the UHV analy sis chamber are described elsewhere ${ }^{3-39}$ The electron beam energy at 3 $\mathrm{keV}$ was used for retarding field AES (SpectaLEED 4-Grid. Omicron). The AES experiments were performed with $1+0 \mu \mathrm{A}$ of a beam current $0.3 \mathrm{~mA}$ of an emission current. $1.17 \mathrm{~A}$ of a filament current, and $75 \mu \mathrm{A}$ of a target current. The survey scan range for AES applied in this work was from 5 to $600 \mathrm{eV}$. The parameters for AES survey scan were $1 \mathrm{eV}$ of an energy step. $3 \mathrm{mV}$ of a lock-in sensitivity and $100 \mathrm{~ms}$ of a lock-in time constant. The high resolution $\mathrm{AE}$ spectra were taken at the ranges for zirconium. carbon. and oxygen were from 70 to $180 \mathrm{eV}, 240$ to $300 \mathrm{eV}$. and 280 to $540 \mathrm{eV}$, respectively, with $0.2 \mathrm{eV}$ of energy step and other factors were kept the same as survey scan. In AES study'. sample temperature was raised stepwisely from $190 \mathrm{~K}$ up to $503,628.653,753$. and $843 \mathrm{~K}$ then cooled down the sample to adsorption temperature for investigation of thermal effect on the $\mathrm{C}_{2} \mathrm{D}_{5} \mathrm{OD} / \mathrm{Zry}-4 \mathrm{sy}$ stem. These temperatures were chosen in according to the results of TPD experiment. After sample was cooled down. AES data were collected.

\section{Results and Discussion}

Figures $\mathrm{I}$ (a) and (b) show the representative thermal desorption spectra of 2 amu $\left(\mathrm{H}_{2}^{+}\right.$or $\left.\mathrm{D}^{-}\right)$and 4 amu $\left(\mathrm{D}_{2}^{+}\right)$. respectively after different $\mathrm{C}_{2} \mathrm{D}_{5} \mathrm{OD}$ exposures at $190 \mathrm{~K}$ of adsorption temperature. The gas exposures are presented by langmuir $\left(1 \mathrm{~L}=1.0 \times 10^{-6} \mathrm{Torr} \cdot \mathrm{s}\right)$ unit. When the exposure of gas

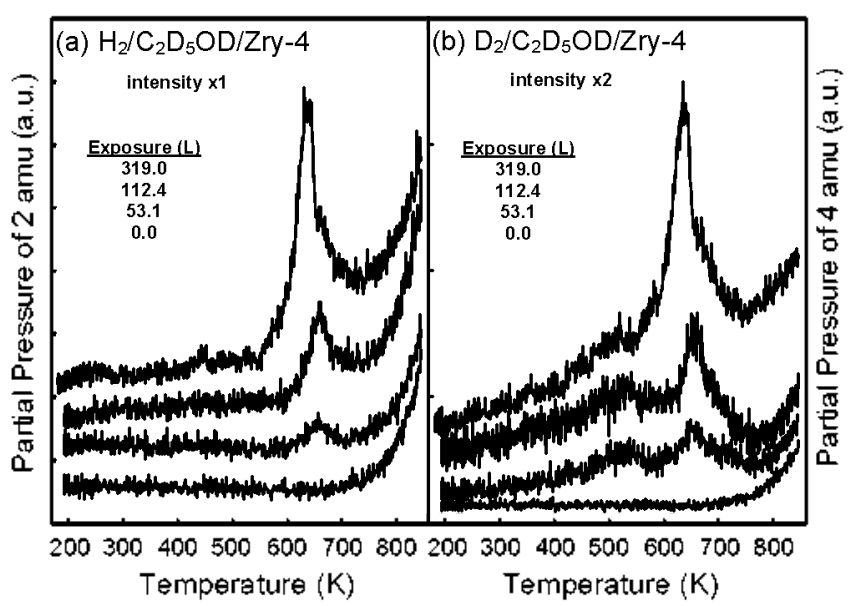

Figure 1. Temperature programmed desorption spectra of (a) 2 amu and (b) 4 annu following $C, D \leqslant O D$ adsortion on Zircaloy 4 at $190 \mathrm{~K}$. The numbers in the figure represent the exposure in langmuir unit (L). The notations used in the title of these figures, such as $\mathrm{H}_{2} / \mathrm{C}_{2} \mathrm{D}_{5} \mathrm{OD} /$ $\mathrm{Zrv}-4$, means $\mathrm{H}_{2}$ evolution after $\mathrm{C}_{2} \mathrm{D}_{5} \mathrm{OD}$ dosed on the $\mathrm{Zry}-4$ surfaces. was lower than $50 \mathrm{~L}$, no noticeable desorption was observed. Even ultra pure deuterized ethanol was used for this study hydrogen exchange could be occurred in the gas handling line. Because of the hydrogen exchange, $\mathrm{H}_{2}$ desorption peak was detected. The hydrogen ( $2 \mathrm{amu})$ thermal desorption peak was observed at around $660 \mathrm{~K}$ at $53 \mathrm{~L}$ of ethanol exposure which increased in intensity with increasing $\mathrm{C}_{2} \mathrm{D}_{5} \mathrm{OD}$ exposure. The desorption peak temperature shifted to lower temperature according to the increase of gas exposure. This phenomenon could be explained by the second-order desorption kinetics. Especially. note the $\mathrm{D}_{2}$ evolution (Figure 1 (b)). the desorption peaks appeared both $\sim 520 \mathrm{~K}$ and $\sim 650 \mathrm{~K}$ overlapped with broad desorption background from $\sim 300 \mathrm{~K}$ to $750 \mathrm{~K}$. This broad desorption background implies that complicate desorption kinetics was involving in $\mathrm{D}_{2}$ desorption. The peak position of low temperature desorption feature $(520 \mathrm{~K})$ was constant with increasing the exposures of adsorbate indicating that the desorption of $\mathrm{D}_{2}^{+}$was the first-order desorption verified by peak-shape analysis. The high temperature desorption feature $(660 \mathrm{~K})$ gradually increased in intensity with exposure and shifted to lower temperature. It could indicate the secondorder desorption kinetics.

The desorption feature of $\mathrm{D}_{2}$ at low temperature was almost saturated at $53 \mathrm{~L}$ of $\mathrm{C}_{2} \mathrm{D}_{5} \mathrm{OD}$ exposure but the feature at high temperature was grown at the exposure increased (Fig. l(b)). This could be explained that the low temperature feature was developed by the deuterium existed near the zircaloy -4 surface region which was easily saturated by $53 \mathrm{~L}$ of exposure and the other was evolved by the deuterium stayed in the bulk region. Higher exposure of $\mathrm{C}_{\hat{1}} \mathrm{D}_{5} \mathrm{OD}$. higher concentration of deuterium in the bulk is. The high temperature feature was only detected in $\mathrm{H}_{2}$ desorption because the hydrogen existed in the bulk before $\mathrm{C}_{2} \mathrm{D}_{5} \mathrm{OD}$ exposure was desorbed (Fig. 1(a)).

Figure 2 shows the AES survey spectra of $C_{2} D_{5} \mathrm{OD} / \mathrm{Zry}-4$ sy stem with various annealing tenperatures. The intensity of $\mathrm{Zr}(\mathrm{MNV})$ Auger peak decreased after $C_{2} D_{5} \mathrm{OD}$ dosing on $\mathrm{Zry}-4$ and then increased by annealing the sample as we expected. When the sample was annealed to higher tempera-

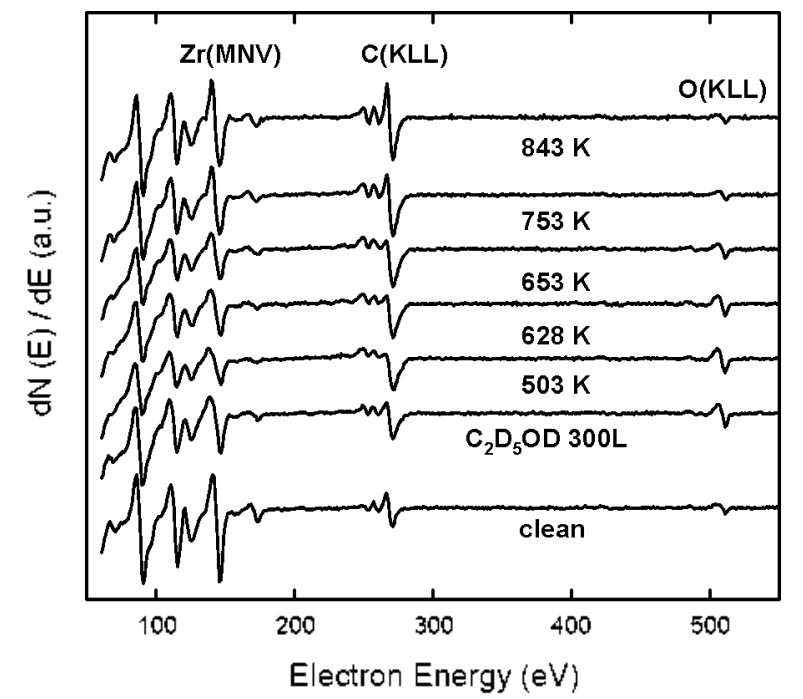

Figure 2. Survey Auger electron spectra of the $\mathrm{C}_{2} \mathrm{D}_{5} \mathrm{OD}$ dosed $\mathrm{Zry}-4$ surfaces. 
(a) Zr features

(b) $\mathrm{c}(\mathrm{KLL})$

(c) $O(\mathrm{KLL})$

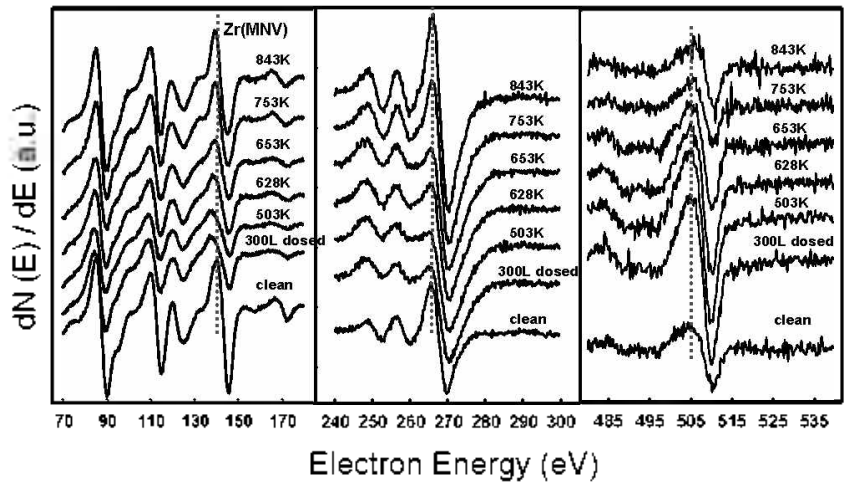

Figure 3. (a) High resolution Auger electron spectra of the Zr features including $\mathrm{Zr}$ (MNV, $147 \mathrm{eV}$ ). (b) AES of the $\mathrm{C}$ (KLL, $270 \mathrm{eV}$ ) peak and (c) AES spectra of the $O(\mathrm{KLL}, 510 \mathrm{eV})$ peak. The vertical lines are put on the peak maximum position of the clean surface for clarity of peak shifting.

ture, the intensity of $\mathrm{O}(\mathrm{KLL})$ Auger peak decreased but that of $\mathrm{C}(\mathrm{KLL})$ increased. To stidy the details of the surface chemistry: high resolution AES experiments were carried out for the energy ranges of $\mathrm{Zr}(\mathrm{MNV}) \mathrm{C}(\mathrm{KLL})$, and $\mathrm{O}(\mathrm{KLL})$.

Figures 3 (a). (b). and (c) show the high resolution AE spectra of zirconium. carbon, and oxygen regions. respectively. We collected AE spectra after stepwise annealing of the sample to our interested temperatures which were chosen considering with the TPD spectra shown in Figures 1, at and after the desorption peak maximum. The peak positions of $\mathrm{Zr}(\mathrm{MNV})$. $\mathrm{C}(\mathrm{KLL})$. and $\mathrm{O}(\mathrm{KLL})$ are assigned at the electron kinetic energy of 147.270 , and $510 \mathrm{eV}$. respectively. The vertical lines in the figures added for clarity. The intensity of $\mathrm{Zr}(\mathrm{MNV})$ feature was decreased after $300 \mathrm{~L}$ of $\mathrm{C}_{2} \mathrm{D}_{5} \mathrm{OD}$ exposure and gradually recovered by annealing as we expected. We should notice in Figure 3 (a) that the $\mathrm{Zr}$ (NMV) AE feature shifted to lower electron energy region $(\sim 2.5 \mathrm{eV})$ than the original peak position followed by $C_{3} D_{5} O D$ dosing then shifted back to higher electron energy by increasing the temperature of amnealing. This implies that the oxidation state of zirconium changed from metallic zirconium to zirconium oxide then back to nearly metallic zirconium by annealing. The change of zirconium oxidation state was supported by the AE spectra of oxygen (Figure 3 (c)) as well. As we can see in Figure 3 (c). the $\mathrm{O}(\mathrm{KLL})$ peak was increased by $300 \mathrm{~L}$ of $\mathrm{C}_{2} \mathrm{D}_{5} \mathrm{OD}$ exposure. Then the intensity of $O(K L L)$ was decreased by annealing to the level before dosing of $C_{5} D_{5} O D$. The Auger electron intensity of $\mathrm{C}(\mathrm{KLL})$ stayed almost constant until the sample temperanure reached to $628 \mathrm{~K}$ shown in Figure 3 (b). After this temperature C(KLL) intensity increased by annealing. This could be happened that the defragmented carbon in subsurface region was diffused out after the constituents near the surface were desorbed out to vacuum by annealing. These carbon diffused from the subsurface region was not cleaned before 10 cycles of Ar sputtering process. We should notice that the line shape of $\mathrm{C}(\mathrm{KLL})$ shown in Figure 3 (b). The line shape of $\mathrm{C}(\mathrm{KLL})$ feature. i.e. oscillation of peak at low kinetic energy side. could be used to differentiate carbidic and graphitic carbon reported by Gomer's group. ${ }^{\text {th }}$ The peak oscillation of low kinetic energy

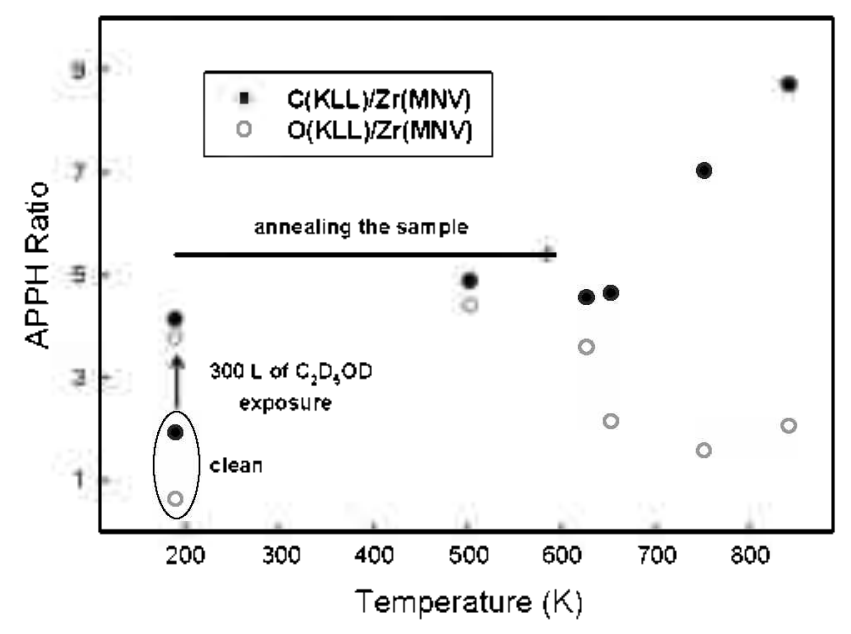

Figure 4. Auger peak-to-peak heights (APPH) ratio versus annealing temperature. Filled circles represent for $C(\mathrm{KLL}) / Z \mathrm{r}(\mathrm{MNV})$ and open circles represent for $O(K L L) Z Z(M N V)$. The data inside of the circle bottom of the left in the figure present APPH ratios of $\mathrm{C} / \mathrm{Zr}$ and $\mathrm{O} / \mathrm{Zr}$ of the clean Zry-4 surface.

region of $\mathrm{C}(\mathrm{KLL})$ was dininished when the sample was annealed to $503 \mathrm{~K}$, then the oscillation was recovered with further annealing the sample to $843 \mathrm{~K}$. This implies that the dominant carbon state of the $\mathrm{C}_{2} \mathrm{D}_{5} \mathrm{OD} / \mathrm{Zry}-4$ changed from carbidic through graphitic to carbidic carbon on the surface by annealing. Tanaka et $a l$. have reported the formation of hybrid surface of carbide and graphite layers at $630-640 \mathrm{~K}$ on $\mathrm{Ni}$ surface by dispropomation reaction of $\mathrm{CO}^{\text {tl }}$ Further study needs to verify the carbon state by work function measurement for this systent.

Figure 4 shows the Auger peak-to-peak height (APPH) ratios of $\mathrm{C}(\mathrm{KLL}, 270 \mathrm{eV}) / \mathrm{Zr}(\mathrm{MNV}, 147 \mathrm{eV})$ and $\mathrm{O}(\mathrm{KLL}, 510$ $\mathrm{eV}) / \mathrm{Zr}(\mathrm{MNV})$. The APPH ratios of $\mathrm{C} / \mathrm{Zr}$ and $\mathrm{O} / \mathrm{Zr}$ are 1.91 and 0.62 . respectively for the clean surface. The APPH ratios are calculated concerning with Auger sensitivity factors of the elements. The both ratios are increased after $300 \mathrm{~L}$ of deuterized ethanol dosing. and nearly stayed in constant level until the sample was heated to $628 \mathrm{~K}$. When the sample was heated over $653 \mathrm{~K}$. the ratio of $\mathrm{C} / \mathrm{Zr}$ increased gradually but that of $\mathrm{O} / \mathrm{Zr}$ decreased nearly back to the clean surface level. The carbon diffused onto the surface region by heating formed carbide form with zirconium, because of its small diffusion coefficient. ${ }^{42}$ The diffused out surface oxygen with large diffusion coefficient could be diffused into the bulk caused relatively lower surface contents of oxygen than that of carbon. These phenomena is consistent with the observation reported by other group. ${ }^{43.44}$

\section{Conclusions}

The surface chenistry of $\mathrm{C}_{2} \mathrm{D}_{5} \mathrm{OD}$ on $\mathrm{Zry}+4$ surface was investigated using AES and TPD methods. Isotopic hydrogen was detected from deuterized ethanol dosed $\mathrm{Zry}-4$ surfaces at two different desorption temperature regions accompanying with broad desorption background. This shows the possibility of using hydrocarbon derivatives for the source of hydrogen used in fuel cell. The lower temperature feature at around $\mathbf{5 2 0}$ $\mathrm{K}$ stayed the same temperature increasing $\mathrm{C}_{5} \mathrm{D}_{5} \mathrm{OD}$ exposure. 
This implies $\mathrm{D}_{2}$ desorption is first-order desorption kinetics. The TPD peak of $\mathrm{D}_{2}$ at around $650 \mathrm{~K}$ was shifted to lower desorption temperature as the exposure of $\mathrm{C}_{2} \mathrm{D}_{5} \mathrm{OD}$ increased. In $\mathrm{AES}$ study, the $\mathrm{Zr}(\mathrm{MNV})$ Auger peak was shifted about $2.5 \mathrm{eV}$ from $147 \mathrm{eV}$ to lower electron energy followed by $300 \mathrm{~L}$ of $\mathrm{C}_{2} \mathrm{D}_{5} \mathrm{OD}$ dosed. This implies metallic zirconium was oxidized by deuterized ethanol adsorption then reduced back to metallic zirconium by annealing because the oxygen near the surface was depopulated by heat treatment.

Acknowledgments. This work was supported by the Korea Research Foundation Grant fiunded by the Korean Government (MOEHRD) (KRF-2006-331-C00146).

\section{References}

1. Ha, Y. K.: Han, S. H.: Park, S. D.: Park, Y. S.: Kim, W. H. Chemical hteraction between 10 , Fuel and Zinalov Clad: Korea Atomic Energy Research Institute: Report KAERI/AR-697/2004.

2. Wilson, P. D. The Biclear Fuel Cucle: From Ore to Wastes; Oxford University Press: New York, 1996; p 89.

3. Ravi Shankar, A.; Raju, V. R.; Narayana Rao, M.; Kamachi Mudali, U.; Khatak, H. S.; Rai, B. Corf. Sci. 2007, 49, 3527.

4. Sundaram, C. V. T. Indion I. hetals 1986, 39, 12

5. Yao, M. Y.; Zhou, B. X.: Li, Q.; Liu, W. Q; Geng, X; Lu, Y. P. J. Nitct. Mater. 2008, 37t, 197.

6. Wan, Q: Bai, X.: Zhang. X. Mater Res. Bull. 2006, 41,387

7. Kim, W.; Jung, K. S.; Choi, B. H.: Kwon, H. S.; Lee, S. J.: Han, T. G.: Guseva, M. I. Atamanov, M. V. Surf. Coat. Technol 1995, 76,595

8. Chen, X. W: Bai, X. D.: Dentg, P. Y : Peng, D. Q: Chen, B. S. Nucl Instr and Meth B $\mathbf{2 0 0 3}, 211,512$.

9. Liu, X.: Bai, X.: Zhou, C.: Wei, L. Surf. Coat Techmol 2004. 182,138 .

10. Abolhassani, S.; Dadras, M.; Leboeuf, M.; Gavillet, D. J. Sirct. Afater. 2003, 321, 70

11. Bozzano, P. B.; Ipohorski, M: Versaci, R. A. Acta lficróscopica 2004, 13, 47

12. Hotmann, P. J. Wird. Hater: 1999, 270,194

13. Moulin, G.: El Talhhan, R.; Favergeon, I.: Viennot, M.: Berger, P. Hater. Sci. Formm 2006, 522-523, 425

14. Bai, X. D: Wang, S. G.: Xu, T.: Bao, T.: Chen, H. M.; Fan, Y. D. J. Nucl Mater 1998, 254, 266

15. Li, T.; Bai, X.; Zhang, D; Li, H. Appl. Surf. Sci. 2006, 252, 7436.

16. Stojilovic, N.; Ramsier, R. D. J. Kucl Mater. 2006, 350, 163.
17. Berger, P.: El Tahhann, R.: Moulin. G.: Viennot, M. Kucl Insti. and Meth. B 2003, 210, 519 .

18. Takagi, I:; Hashizumi, M: Yamahami, A.; Maehara, K.: Higashi, K. J. Nicl. Nater. 1997, 2ł8, 306.

19. Steinbrïch, M. J. Nicl. Mater. 2004, 334, 58

20. Meyer, G.: Kobrinsky, M.; Abriata, J. P.: Bolcich, J. C. J. Mucl. Mater. 1996. 229. 48 .

21. Gómez, M. P.; Domizzi, G.; López Pumarega, M. I.; Ruzzante, J. E. J. Nitct. Hater. 2006, 353,167

22. Kim, S. I.; Kim, K. H.: Baek, J. H.; Choi, B. K.; Jeong, Y. H.; Jung, Y. H. J. Nucl Mater. 1998, 256, 114.

23. Femández, G. E; Meyer, G.; Peretti, H. A. J. Allows \& Compd. $2002,330,483$

24. Tupin, M.; Pijolat, M.: Valdivieso, F.: Solstelle, M.; Frichet, A:; Barberis, P. J. Nucl Aater 2003, 317, 130.

25. Kim, J. H.: Lee, M. H.: Choi, B. K.. Jeong, Y. H. J. Aucl Mater. $\mathbf{2 0 0 7}, 362,36$

26. Kim, T. H.; Lee, M. H.; Choi, B. K. Teong, Y. H. Nucl. Eng. Des. 2005, 235, 67

27. Stojilovic, N.: Ramsier, R. D. Appl. Suf. Sci. 2006, 252, 5839

28. Park, K. H: Cho, Y. C; Kim, Y. G. J. Nitl . Hater 1999, $270,154$.

29. Stojilovic, N.; Ramsier, R. D. Surf. Interface Anal. 2006, 38, 139.

30. Hong. H. S.; Moon, J. S.: Kim, S. I, Lee, K. S. J. Nucl Mater. 2001, 297, 113

31. Bai, X; Xu, T.; He, F.; Fan, Y. Nitl histr and Heth. B 2000, 160,49 .

32. Stojilovic, N.; Bender, E. T; Ramsier, R. D. J. Nucl. Mater: $2006,3+8,79$.

33. Sheng, P. Y.: Bowmaker, G. A.; Idriss, H. Appl Catahsis A; General 2004, 261, 171

34. Silva, A. M.; BArandas, A. P. M. G.; Costa, L. O. O.; Borges, L. E. P.: Naltoso, L. V.: Noronga, F. B. Cata. Today 2007, 129, 297.

35. Barthos, R:; Szechenyi, A.; Koós, A.: Solymosi, F. Appl Catal. A: Gen, 2007, 327, 95

36. Sheng, P. Y; Chiu, W. W.; Yee, A.; Norrison, S. I; Idriss, H. Catal. Toda, 2007, 129, 313.

37. Kwon, T. H.; Youn, S. W.: Kang, Y. C. Bull. Korean Chem. Soc. 2006, 27, 11 .

38. Oh, K. S.; Kang, Y. C. Bull. Korean Chem. Soc. 2007, 28, 1341

39. Jung, H. Y.; Kang, Y. C. Bull. Korean Chem. Soc. 2007, $28,1751$.

40. Whitten, J. E.: Gomer, R. Surf. Sci. 1996, 3+7, 280.

41. Nakamura, I.: Hirano, H.: Xie. M.: Matsuo, I.: Yamada. T.: Tanaka, K. Sirf. Sci. 1989, 222(1,2), L809.

42. Foord T. S: Goddard, P. J.; Lambert, R. M Sutf. Sci. 1980, $94,339$.

43. Stojilovic, N.; Weber, D. W.: Ramsier, R. D. Appl. Suf. Sci. $2003,218,188$

44. Stojilovic, N.; Farkas, N.; Ramsier, R. D. Appl. Surf. Sci. 2008, $254,2866$. 